\title{
Nanomechanical Behaviour of Individual Phases in WC-Co Cemented Carbides, from Ambient to High Temperature.
}

\author{
F. De Luca1*, H. Zhang1, K. Mingard ${ }^{1}$, M. Stewart ${ }^{1}$, B. M. Jablon ${ }^{1,2}$, C. Trager- \\ Cowan², M. G. Gee ${ }^{1}$ \\ ${ }^{1}$ National Physical Laboratory, Hampton Road, Teddington, Middlesex, TW11 OLW, UK. \\ 2 University of Strathclyde, 107 Rottenrow East, Glasgow G4 0NG, UK.
}

\begin{abstract}
The dependence of the mechanical behaviour of individual phases in WC-Co on microstructural parameters such as grain size and orientation were investigated by means of nanoindentation and electron microscopy. A broad range of WC grain dimensions, from about 1 to $1000 \mu \mathrm{m}^{2}$, were selected and subsequently indented to investigate any size effect. A decrease in hardness as a function of grain dimensions was observed, due to an increase in dislocation mobility in larger grains. Whilst the binder phase only exhibits a hardness of about $11 \mathrm{GPa}$, the hardness of WC grains was measured about 29 and $53 \mathrm{GPa}$ for the prismatic and basal orientations, respectively, in ambient conditions. All WC orientations exhibited a similar decrease in hardness with temperature, up to $700{ }^{\circ} \mathrm{C}$. Damage mechanisms occurring in WCCo during nanoindentation were investigated for the different grain orientations at various temperatures. The damage was visualised using electron microscopy near the residual indent coupled with Focused Ion Beam (FIB) sectioning across the indent. The three-dimensional distribution of plastic deformation across multiple grains in the vicinity of an indent was examined using Electron Channelling Contrast Imaging (ECCl). ECCI micrographs enabled the observation of crystal defects, especially dislocations, and slip lines as well as the entire plastic zone. The defect density and spatial distribution in the deformed WC grains were compared to that of untested WC grains to identify the type of deformation originating from spherical indentation. The work provides important information on the relationship between WC-Co microstructure and performance at operating temperatures.
\end{abstract}

Keywords: Nanoindentation, mechanical properties, high temperature deformation, microstructure, electron microscopy.

\section{Introduction}

Cemented carbides, such as tungsten carbide-cobalt composites (WC-Co), also known as hardmetals, are used as cutting, machining, and forming tools because of their high hardness and strength combined with high fracture toughness and wear resistance [1-3]. While WC grains are hard and brittle non-oxide ceramics with a simple hexagonal crystal structure $(\mathrm{a}=2.900 \AA$ and $\mathrm{c}=2.831 \AA$, type $\mathrm{P}-6 \mathrm{~m} 2)$ [4], the cobalt metallic binder-phase is fairly ductile and allows the material to tolerate damage and undergo deformation $[5,6]$. At the micrometre length scale, WC-Co appears heterogenous, with mechanical performance governed by its microstructure. Over the past decades, the mechanical behaviour of the different phases in WC-Co has been investigated to shed light on the close relationship between performance and microstructure design [5, 7-11]. Particular attention has been focused on the local properties of WC grains at the micro- and nano-scales, revealing 
anisotropic mechanical behaviour; at the scale of WC single crystals, mechanical anisotropy has been reported for the different crystallographic orientations of WC, from its basal to prismatic planes [7-19]. While final fracture of WC-Co occurs via crack propagation trans-granularly through both phases and inter-granularly at WC-WC and WC-Co interfaces, plastic deformation also operates in the brittle WC ceramic phase prior to failure $[6,13,15$, $19,20]$, with significant impact on the overall deformation process of the material [21]. Therefore, understanding the deformation mechanisms in WC grains at the nanoscale is of great importance. While a lot of effort has been made to improve the performance of WC-Co though microstructural design, gathering mechanical properties from the different phases and WC crystal orientation at room temperature, very little information has been collected at high temperature $[14,22]$. Vickers hardness measurements, at temperatures ranging from ambient to $1000{ }^{\circ} \mathrm{C}$, have been conducted on several WC-Co grades with varying Co binder phase proportions and WC grain sizes, revealing significant decrease in hardness of the overall material, especially at temperature higher than $600{ }^{\circ} \mathrm{C}$ [23]. Since the operating temperatures of WC-Co, when used as tools, can reach temperatures as high as 700 to $800^{\circ} \mathrm{C}$, it is therefore crucial to understand how the material performs in these extreme conditions as well as its limitations, focusing on individual phases. Hence, the nanomechanical behaviour of WC-Co needs to be investigated at varying temperatures to understand the basic physical processes of the material for better designs required for engineering applications. Information about the mechanical anisotropy of WC crystal are strongly needed at elevated temperatures as they provide crucial experimental data for modellers to predict the effect of microstructural changes at operating temperature. More generally, understanding the high temperature performance of individual phases could represents a way towards the design of WC-Co with better performance at high temperature, through synergistic effect. Hardness measurement has been intensively used in the development of microstructures as it allows for a direct comparison of grades and is indicative of potential improvement in performance. In addition to measuring the local mechanical performance of WC-Co, understanding the deformation behaviour of the material when subject to extreme conditions will also provide crucial information for the development of new microstructural designs. High temperature nanoindentation has emerged over the past decade [24-28] as a technique offering the possibility to investigate the local mechanical behaviour of materials in their operating conditions at the micro- and nano-scale, which is strongly desirable for the proposed study; thermally stabilised nanoindentation has already been successfully performed on a broad variety of materials, at temperatures up to $1000^{\circ} \mathrm{C}[26,29]$.

In the present study, we aimed to extract valuable mechanical information from WC-Co grades, such as the hardness of the different phases but also the hardness dependency of WC on crystal orientation at temperatures ranging from ambient to $700{ }^{\circ} \mathrm{C}$. Size effect was also investigated in WC grains with dimensions covering 3 orders of magnitude, from 1 to $1000 \mu^{2}$. Understanding of the microstructural mechanisms behind these property variations was sought by means of electron microscopy, using Electron Channelling Contrast Imaging $(\mathrm{ECCl})$ combined with Focused lon Beam (FIB) cross sections. These were used to observe the formation, accumulation and spread of damage and plastic deformation around spherical nanoindentation in individual WC grains as a function of orientation and temperature. Correlation between these observations and changes in mechanical properties and deformation mechanisms of WC crystals is discussed. 


\section{Experimental}

A methodology was developed to extract the hardness of individual WC grains and Co binder phase, in three different grades of WC-Co, with varying grain dimensions (Tab.1). While large nanoindentation arrays have been performed to investigate the mechanical response of individual phases in WC-Co using statistical analysis [11], here individual WC grains and Co binder phase were directly targeted followed by subsequent indent validation (Fig.1). Our study allowed for the mechanical investigation of individual grains and Co binder only, without having to take into account interfacial interaction, via a limited number of indents. The method was therefore cost-effective, especially at high temperature, where rapid wear of the indenter occurs.

Table 1. WC-Co grades. Properties of the different WC-Co grades tested.

\begin{tabular}{ccc}
\hline WC-Co grade & $\begin{array}{c}\text { Cobalt binder phase / } \\
\text { wt.\% }\end{array}$ & $\begin{array}{c}\text { Average WC grain size / } \\
\boldsymbol{\mu m}\end{array}$ \\
\hline $6 \mathrm{~A}$ & 6 & $\approx 1$ \\
\hline $11 \mathrm{E}$ & 11 & $\approx 5$ \\
\hline $6 \mathrm{EC}$ & 6 & $\approx 15$ \\
\hline
\end{tabular}

\section{Minimum grain size determination}

Nanoindentation was performed on the three WC-Co grades, allowing for the investigation of a broad range of WC grain dimensions and, therefore, any potential grain size effect. While large grains (few tens of micrometres wide) can easily be tested, it was important to identify the limitation of our method, namely, determining the smallest grain dimensions from which a reliable hardness value could be extracted. Hence, the scale limitation of the method was first assessed by conducting a nanoindentation array of 100 indents at room temperature in WC-Co with a spacing of $10 \mu \mathrm{m}$, using a multiloading procedure (10 loading cycles) with loads ranging from 0.5 to $100 \mathrm{mN}$. The ratio of the applied load over the square stiffness $\left(P / S^{2}\right)$ was plotted as a function of the indentation depth (Fig. $\left.1 \mathrm{~A}\right)$. Because $P / \mathrm{S}^{2}$ is independent of the area function of the indenter, it was used to highlight the indentation depth range in which indentation size effect (ISE) occurs [8]. A minimum indentation depth of about $80 \mathrm{~nm}$ was determined to avoid ISE and extract reliable hardness values from the individual grains of WC-Co. At greater depth, $\mathrm{P} / \mathrm{S}^{2}$ values become independent to the indentation depth, with scatter progressively decreasing as the mechanical response of the overall WC-Co composite material is being probed rather than that of individual phases; when indenting WCCo at low depth (around $100 \mathrm{~nm}$ ), only individual phases (individual WC grain or the softer Co binder phase) with very different hardness are probed, as compared to indentation made at a depth of $1 \mu \mathrm{m}$, where multiple phases are probed all together.

From the latter minimum indentation depth and the aspect ratio (approx. 7) of the Berkovich indenters used, the minimum grain length required to confine the plastic field within the individual grain of interest (the distance between the indent and the nearest boundary) was calculated. According to a recent study, a minimum spacing of about 8-10 times the maximum indentation depth (based on Berkovich indents) is needed between two adjacent indents in order to avoid overlapping stress fields [30]. The latter implies that the indentation stress field propagates along a distance about 4-5 times the maximum indentation depth. 
Therefore, for single indent, a minimum grain length of about $500 \mathrm{~nm}$ was deemed necessary to contain the indentation stress field, which corresponds to a minimum grain area of about $0.8 \mu \mathrm{m}^{2}$. Hence, grains with dimensions larger than $1 \mu \mathrm{m}^{2}$ were tested.

\section{Grain and phase identification}

Individual WC grains and Co binder phase in WC-Co were identified using a Scanning Electron Microscope (SEM) (Zeiss Auriga, Carl Zeiss, Jena, Germany) equipped with an Electron Backscatter Diffraction (EBSD) detector (Oxford Instruments, Nordlys F), via the acquisition of inverse pole figures (IPF) and maps with IPF orientation colouring (Fig.1B). While an angular tolerance of $10^{\circ}$ was used to identify grains as being (0110) or $(\overline{1} 2 \overline{1} 0)$ prismatic grains (primary and secondary prismatic planes), a tighter angular tolerance of $5^{\circ}$ was used in the identification of (0001) basal grains WC. This was done because previous work $[13,16]$, revealed the sharpest drop in hardness of WC grains between 0 and $5^{\circ}$ away from the basal plane orientation. This highlights the importance of carefully selecting WC basal grains.

\section{Indenter positioning and validation}

Because of the need to accurately position the indenter tip on individual grains, as small as $1 \mu^{2}$, while maintaining a minimum grain distance of $500 \mathrm{~nm}$ between the indenter and the nearest grain boundary, topographic maps of the WC-Co samples were acquired by scanning the indenter over the surface with a low contact force between it and the sample, of about $1 \mu \mathrm{N}$. Mechanical polishing of WC-Co predominantly removed the soft Co binder phase, which followed by ion polishing, allowed for a flat surface finish with topographical steps between the two phases. The latter facilitated the topographical imaging of the sample microstructure. Therefore, WC-Co microstructures with sub-micrometre grains were imaged, enabling an accurate positioning of the indenter over the grain or Co phase identified from the EBSD map (Fig.1C). A final step, consisting of validating the indents, was performed in a dualbeam Focused Ion Beam-Scanning Electron Microscope (FIB-SEM) (Zeiss Auriga, Carl Zeiss, Jena, Germany). The location and distance between the indents and the nearest grain boundary were measured from the surface view (top left of Fig.1D) in order to confirm that the plastic field generated during nanoindentation remained within the region of interest. Furthermore, the volume of WC grain beneath and across the indent was also investigated by imaging a FIB cross section of the indent (Fig.1D) to verify that the hardness value extracted from the indent was solely representative of the individual WC grain ; a minimum grain volume, beneath the indent, consisting of a semi-sphere with a radius of $1 \mu \mathrm{m}$, would enclose the plastic field and was therefore deemed valid for shallow indents $(<200 \mathrm{~nm})$. 

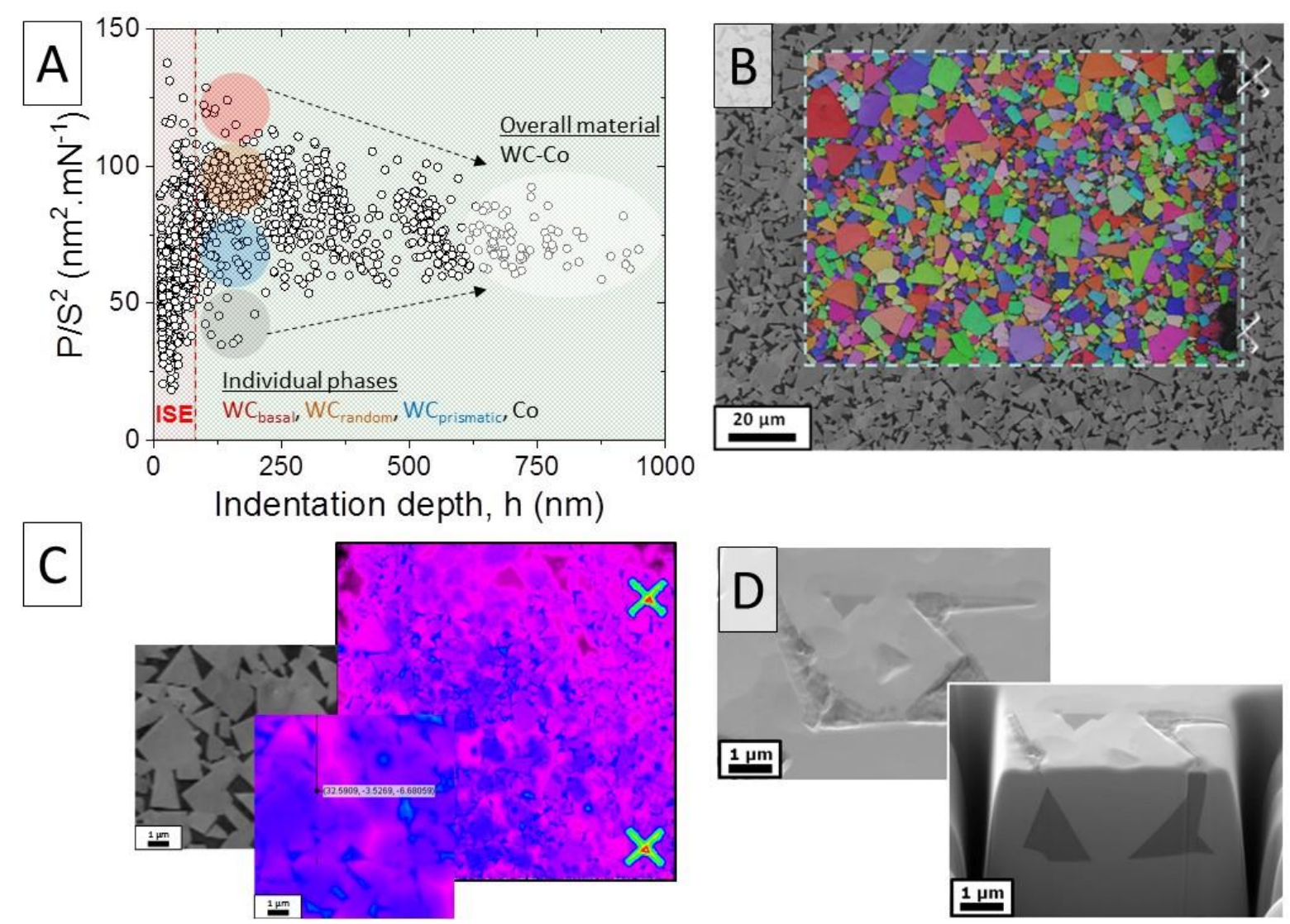

Figure 1. Procedure to extract the hardness of individual WC grains and Co binder phase in WC-Co. Determination of the scale limitation of the method by investigating the indentation size effect (ISE) in WC-Co from the $h=f\left(P / S^{2}\right)$ curve (A) - data to the left of the dotted line (within the red area) are affected by the ISE. Identification of grains and phases in WC-Co by means of IPF acquired by EBSD (B). Topographic scans revealing the microstructure of WC-Co used for fine positioning of the indenter (C). Validation of the location of the indent as well as volume of investigated material (WC) beneath the indent, by means of electron microscopy and focused ion beam (D).

\section{High temperature nanoindentation procedure}

Hardness measurements were performed with a high temperature vacuum nanoindentation system (NanoTest Xtreme, Micro Materials, UK), equipped with resistive heating on both the indenter and the sample. Nanoindentation was performed from room temperature to $700{ }^{\circ} \mathrm{C}$ in steps of $100{ }^{\circ} \mathrm{C}$, under high vacuum $\left(10^{-6} \mathrm{mbar}\right)$, using sharp Berkovich indenters. Even though diamond does not oxidise in vacuum and, therefore, can be used as an indenter at high temperatures, diamond indenters were only used for nanoindentation temperatures ranging from ambient to $300^{\circ} \mathrm{C}$, while cubic Boron Nitride (cBN) indenters were used for temperatures starting from $400{ }^{\circ} \mathrm{C}$ upwards. The specific selection of indenter materials over the whole range of testing temperatures was chosen to avoid dissolution of the diamond into the Cobalt binder phase, which has been reported to occur at high temperatures [28]. The indenters were mounted on a water-cooled heat shield to prevent heat transfer from the testing region to the electronics of the equipment and testing in vacuum suppressed convection currents in the chamber and greatly limiting the transfer of heat to the pendulum and sensors of the nanoindenter.

The different WC-Co samples, with thicknesses of about $1 \mathrm{~mm}$, were mounted on a hot stage using thermally conductive cement (Omegabond OB-600). In addition to the use of 
thermocouples mounted behind the indenter and beneath the hot stage, and because of the formation of a thermal gradient across the thickness of the WC-Co sample, the actual temperature of the sample, near the indentation region, was recorded by use of a third thermocouple directly welded on the surface of the sample. Depending on the conductivity and thickness of the sample, the temperature displayed from the thermocouple attached to the hot stage (thermocouple mounted beneath the heating plate) can differ vastly from the actual temperature on the surface of the sample. Both the indenter and the sample are heated independently, so their temperature was tuned individually to achieve an isothermal contact. An isothermal contact is essential as it avoids change in the geometry of the indenter during indentation, caused by the exchange of heat with the sample and consequent thermal expansion effects. A slight mismatch between the temperature of the indenter and that of the sample surface can lead to drastic deviation in the displacement data and, therefore, critical errors in the measurement of mechanical properties [31, 32]. In order to achieve an isothermal contact between the indenter and the sample surface, both the indenter and the sample were thermally stabilised in near-contact, about $5 \mu \mathrm{m}$ away from one another, to avoid heat transfer when approaching the indenter. Since the indenter is highly conductive and possesses a small thermal mass compared to the sample, its temperature was controlled using a fixed power, which enabled any heat transfer upon contact (change in its temperature) to be seen. The temperature of the sample was also adjusted using proportional-integral-derivative control to keep its temperature constant, near the temperature set for the test. Because the measurement of the thermal drift is indicative of a mismatch between the indenter and the sample surface temperature [27, 33], the temperature of the indenter was carefully adjusted while maintaining the sample surface at the desired temperature, until a thermal drift in the order of $0.1 \mathrm{~nm} . \mathrm{s}^{-1}$ was achieved.

\section{Nanoindentation cycle}

All nanoindentation measurements were performed in load-control, using a maximum load in the range of 10 to $16 \mathrm{mN}$ and 3 to $6 \mathrm{mN}$ for the WC and Co phases, respectively (depending on the area function of the Berkovich indenter), to reach a maximum indentation depth greater than $80 \mathrm{~nm}$. Pre- and post- calibrations of the indenter area function via indirect verification were performed by indenting fused silica (reference material) at varying load/depth. Each nanoindentation cycle consisted of applying the load in $30 \mathrm{~s}$, holding the maximum load for $10 \mathrm{~s}$ and unloading within $20 \mathrm{~s}$. Thermal drift correction data were collected at $90 \%$ unloading for $60 \mathrm{~s}$. For high temperature testing $\left(\geq 100{ }^{\circ} \mathrm{C}\right)$, an additional stabilisation time of $180 \mathrm{~s}$ was used prior to loading, bringing the indenter and sample in close contact to equilibrate any potential thermal transfer. For each indent, the hardness was measured using the Oliver-Pharr method [34, 35]. Additionally, the plastic index of the indented grains was measured at all temperatures as a ratio of the indentation plastic work (area under the P-h curve) over the overall indentation work (plastic + elastic recovery) [36].

\section{ECCl observation of deformation}

Plastic deformation in prismatic and basal WC grains was investigated at different temperatures, by means of spherical nanoindentation ( $5 \mu \mathrm{m}$ radius), from ambient to $600{ }^{\circ} \mathrm{C}$. While sharp indenters are needed to extract accurate hardness values from shallow indents in sub-micrometre domains, on the other hand, spherical indenters generate homogenous plastic deformation around the indent, allowing for an understanding of deformation 
mechanisms. A load of $150 \mathrm{mN}$ was applied to individual grains within $30 \mathrm{~s}$, held for $30 \mathrm{~s}$ and removed within $30 \mathrm{~s}$. The orientation of the grains was identified by EBSD, prior to nanoindentation. The thermal stabilisation method described previously was also used for spherical nanoindentation. The formation of plastic deformation near the spherical indent was investigated by electron microscopy, using the Electron Channelling Contrast Imaging (ECCl) technique [37, 38]. Images were acquired with an accelerating voltage of $30 \mathrm{kV}$, an aperture of $60 \mu \mathrm{m}$ and a working distance of 5 to $7 \mathrm{~mm}$. The so-called "high current mode" was activated. Prior to imaging and in order to observe good contrast in WC grains, an ion polisher (Hitachi, IM4000) was used on WC-Co grades to improve their surface finish. WC grains tested at room temperature were imaged before and after indentation by acquiring a series of $\mathrm{ECCl}$ micrographs, tilting the sample from 5 to $17^{\circ}$ with regards to the electron beam, with a step of $0.2^{\circ}$. For high temperature investigation, the indented WC grains were imaged by tilting the sample stage to an angle of $12^{\circ}$ and then rotating around the sample plane by $180^{\circ}$ while $\mathrm{ECCl}$ micrographs were collected every $2^{\circ}$ to satisfy multiple channelling conditions, as described in previous work [39-41]; tilting and rotating the sample under the electron beam allowed for the visualisation of defect (plastic deformation) with various orientation. In order to maintain the same field of view, each indented WC grains was brought in the rotation centre of the SEM stages, using additional sub-stages ( $\mathrm{X}$ and $\mathrm{Y}$ ) (SmarAct $\mathrm{GmbH}$, Germany). All micrographs were stacked together using FIJI software to create movies [42]; while a single ECCI micrograph cannot highlight all the plastic deformation generated during indentation (typically one diffraction condition satisfied), the movies enable a better visualisation of the complex plastic field near the indent (multiple diffraction conditions satisfied). Cross-section ECCI micrographs were also acquired across the spherical indent by use of FIB. All indented grains for $\mathrm{ECCl}$ investigation were located near the edge of the sample to facilitate imaging of the cross-section. WC-Co material was milled away from the edge of the sample up to the indented grains, forming a $90^{\circ}$ edge near the centre of the spherical indent. The milling direction was kept perpendicular to the edge of the sample, and thus at a random orientation relative to the indented grain, to obtain a clear view of the cross-section via the electron beam while maintaining a low working distance of 5-7 mm. A low current and voltage of $250 \mathrm{pA}$ and $15 \mathrm{kV}$, respectively, were used in order to achieve fine surface finish to visualise good electron channelling contrast across the indented grains. ECCI micrographs of the cross-section were acquired by tilting the cross-section surface to an angle of $12^{\circ}$ with regards to the electron beam, while using the same imaging parameters as previously mentioned for top-surface $\mathrm{ECCl}$.

\section{Results and discussion}

\section{Room temperature nanoindentation}

The direct targeting of individual phases and grain orientations in WC-Co composites and subsequent indentation validation by means of electron microscopy enabled the extraction of local mechanical information at the nanoscale, and more especially the hardness values of individual grains and Co binder phase (Fig.2A), which shows hardness measurements on (011) and ( $\overline{1} 2 \overline{1} 0)$ WC prismatic planes as well as the (0001) WC basal plane. There is significant mechanical anisotropy at room temperature. The two prismatic orientations show the same hardness, about $29 \mathrm{GPa}$ (from at least 50 grains of each prismatic orientation). Under-estimated hardness values, about $38 \mathrm{GPa}$ (from 25 grains), were measured for the basal orientation when using of a large angular tolerance $\left(10^{\circ}\right)$ during the 
identification process of grains via EBSD; a significant drop in hardness (about $30 \%$ ) was previously reported for grains with an orientation about $10^{\circ}$ away from the basal orientation [13]. When reducing the EBSD angular tolerance to $5^{\circ}$, a much higher hardness values, of about 53 GPa was measured (from 10 basal grains). Hence, the hardness of basal grains was measured to be almost twice that of prismatic grains at room temperature, in good agreement with previous studies $[13,14,16]$. These WC hardness values are averaged values from indents made in different grains with varying dimensions (in the order of 1 to $10 \mu \mathrm{m}$ ) and, therefore, represent an overall performance of the WC grains at the investigated length scale. On the other hand, the ductile Cobalt binder phase was found to have a hardness of about 11 GPa, significantly softer than the brittle WC ceramic phase. These results, made in ambient conditions, are in good agreement with other studies also conducted at room temperature [5, $7-9,11,16]$.
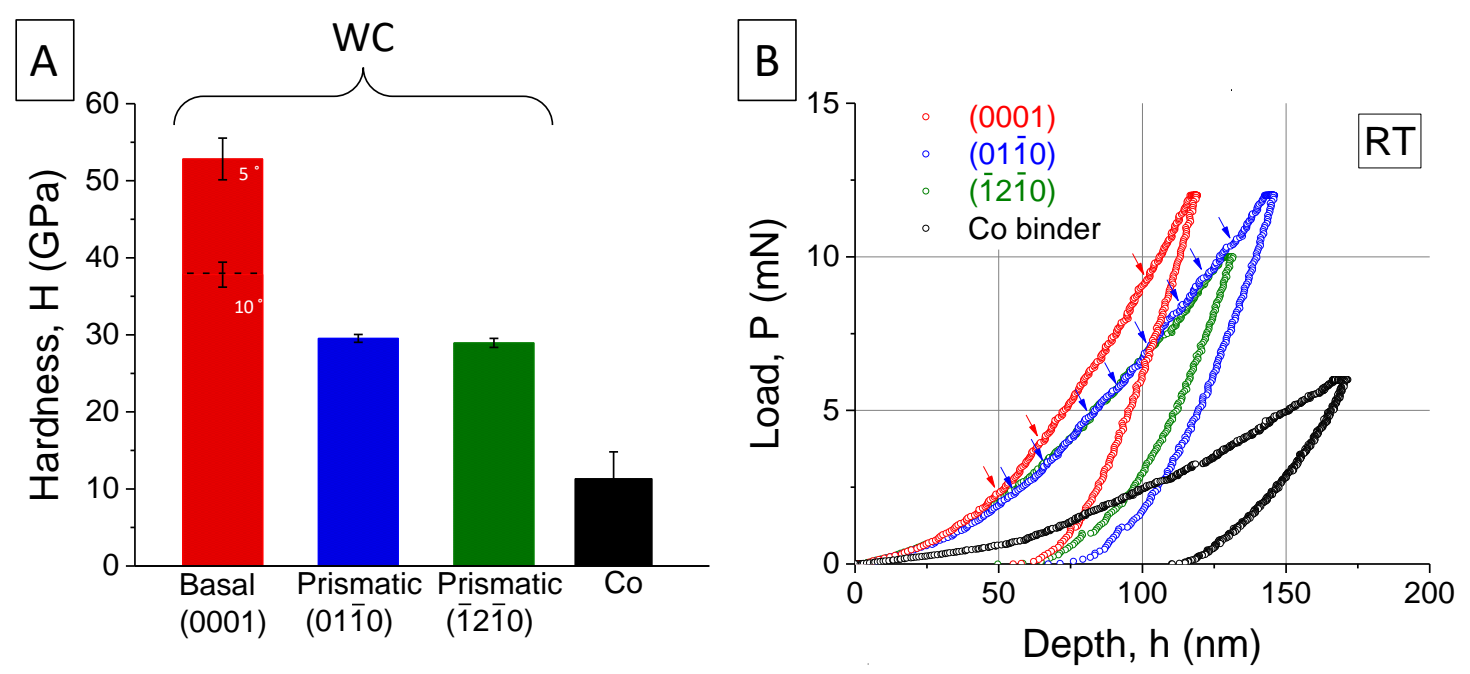

Figure 2. Mechanical properties of individual WC grains and Co binder phase in WC-Co. Hardness measurement of individual phases and WC orientations from WC-Co grades and load displacement curves obtained from the different phases of WC-Co at room temperature ( $A$ and $B$, respectively) - the red and blues arrows pinpoints the occurrence of pop-ins in the loading segments of the P-h curves of the (0001) basal and (011) prismatic grains, respectively.

The load-displacement (P-h) curves obtained from basal and prismatic WC grains at room temperature, clearly show different deformation behaviours for the two crystallographic orientations of WC; even though a similar elastic regime was observed for both WC orientations up to an indentation depth of about $25 \mathrm{~nm}$. At greater depth, plastic deformation in prismatic and basal WC grains displays two distinct plastic trends (Fig.2B). While the P-h curve of prismatic grains exhibit the presence of several pop-ins (plastic flow), that of basal grains is more representative of a work-hardening behaviour with a limited number of pop-ins. The work-hardening ability of basal WC grains has previously been reported and discussed, attributed to the formation of sessile dislocations leading to sink-in near the indent [20]. 

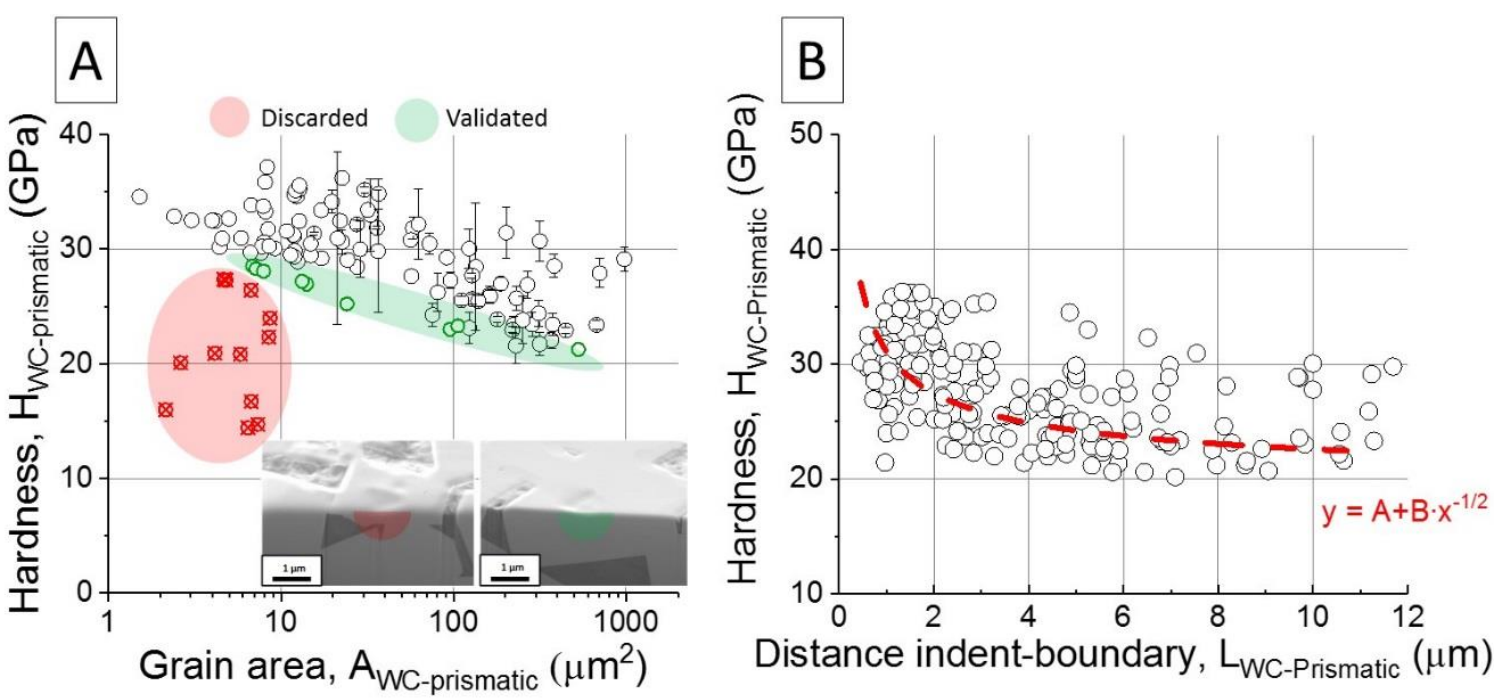

Figure 3. Grain size effect. The hardness values of WC prismatic grains (both $(01 \overline{1} 0)$ and $(\overline{1} 2 \overline{1} 0)$ combined) obtained at room temperature were plotted as a function of the grain surface area (A) - large grains $\left(>10 \mu \mathrm{m}^{2}\right)$ were indented at multiple locations (error bars). Hall-Petch relation was fitted on the hardness data obtained at room temperature from WC prismatic grains as a function of the distance from the indent to the nearest grain boundary (B).

\section{Effect of grain geometry}

The nanoindentation of the three different grades of WC-Co, with varying grain size dimensions, allowed for the investigation of potential grain size effect from the hardness measurements of $(01 \overline{1} 0)$ and $(\overline{1} 2 \overline{1} 0)$ WC prismatic grains ( $\left.\mathrm{H}_{\text {wC-Prismatic }}\right)$ with grain area (Awc-Prismatic) ranging from 1 to $1000 \mu \mathrm{m}^{2}$ (Fig.3A). While only the indents corresponding to the baseline of the data set were validated or discarded, by investigating the volume of material beneath the indent, the hardness of the validated prismatic grains exhibits a clear downtrend as the dimensions of the grains increase (identical for both prismatic orientations). A validation of the low-end hardness data points was thought sufficient to assume that higher hardness data points should be valid for similar grain area. Because the downtrend was continuous throughout the entire dataset, without exhibiting discontinuity between each WC-Co grade tested, this suggests there was no influence of the proportion of Co binder phase or of potential changes in physical properties of the grains as a result of their production method (density, etc.) on the hardness values.

By plotting the hardness of the all prismatic grains as a function of the distance between the indent and the nearest prismatic grain boundary (Lwc-Prismatic), a clear increase in hardness was observed for indents made less than $2 \mu \mathrm{m}$ away from a grain boundary (Fig.3B). The increase in hardness with decreasing $L_{w c}$ is in good agreement with the Hall-Petch relation [43]:

$$
\sigma_{y}=\sigma_{0}+k_{1} L_{W C}^{-\frac{1}{2}}
$$

where $\sigma_{\mathrm{y}}$ is the yield stress and $\sigma_{0}$ and $\mathrm{k}_{1}$ are constants. Here, $\sigma_{\mathrm{y}}$ was replaced by $\mathrm{H}_{\text {wc-prismatic }}$ and the constants $\sigma_{0}$ and $k_{1}$ by arbitrary constants, $A$ and $B$, respectively. When decreasing Lwc to values lower than $2 \mu \mathrm{m}$, the dislocation mobility is affected by the nearest grain boundary. The higher hardness measured for low Lwc is a result of a boundary strengthening 
effect, occurring in grains with restricted dimensions. Whilst the plastic field generated by the indents is believed to have only propagated to a distance of $1 \mu \mathrm{m}$ or less, restrictions in the propagation of the elastic field (travelling further away from the indent) are thought to have also contributed to the reduction in dislocation mobility. The fitting of the hardness values with the Hall-Petch relation allowed for an estimation of the constant $A$, in this instance, representative of the hardness of a large prismatic WC single crystal with no boundary effect $\left(\mathrm{H}_{0, \text { wC-prismatic }}\right)$, about $20 \mathrm{GPa}$, which is in good agreement with results obtained from large WC grains $(\approx 100 \mu \mathrm{m})$ [13]. Boundary strengthening effects was also evidenced in other polycrystalline materials by means of nanoindentation, such as polycrystalline Copper, with similar increase in hardness for grain sizes in the order of 1 to $10 \mu \mathrm{m}$ [44]. Whilst further increase in strengthening effect was reported in Cu grain sizes in the order of $100 \mathrm{~nm}$, an inverse Hall-Petch relation was observed for grains smaller than $50 \mathrm{~nm}$, result of a change of dominance in plastic deformation, namely, from dislocation to grain boundary sliding. The length scale limitation of our technique did not allow for the investigation of such small grains $(<1 \mu \mathrm{m})$. Additionally, due to the nature of the technique, potential strain-hardening behaviour of the material at higher length scales and higher loads has not been investigated.

High temperature nanoindentation
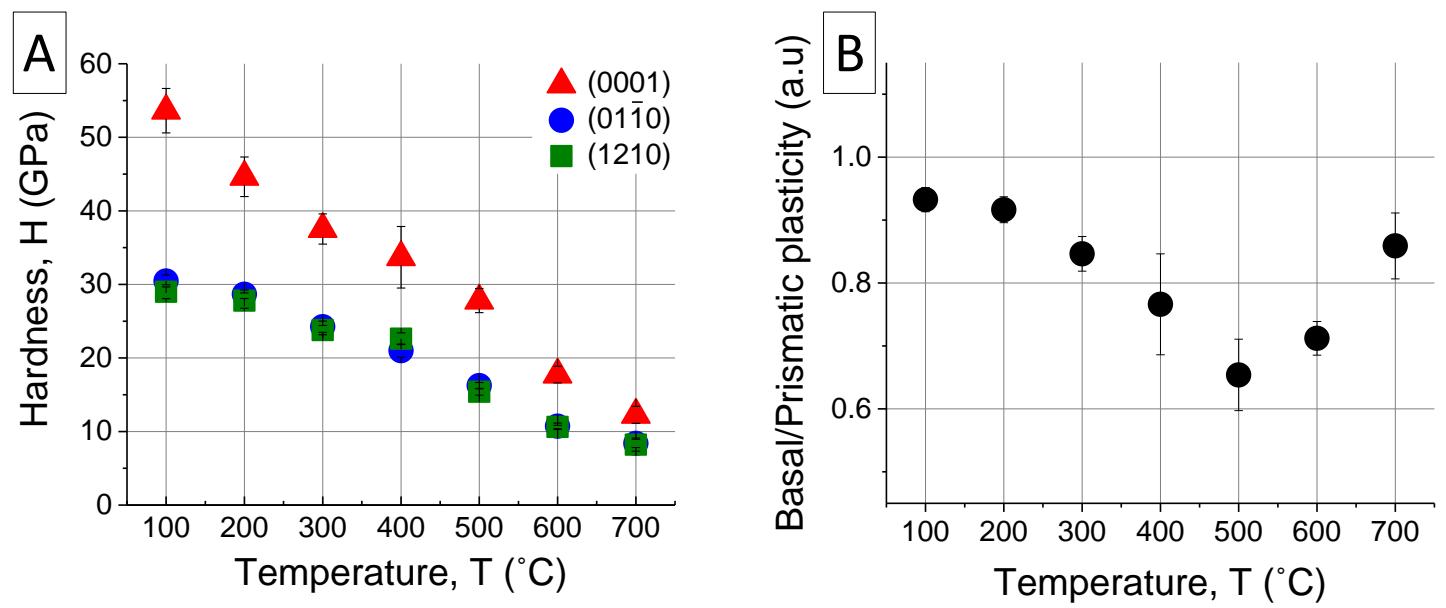

Figure 4. Mechanical properties of WC grains at high temperature. The hardness of the $(01 \overline{1} 0)$ and $(\overline{1} 2 \overline{1} 0)$ prismatic and (0001) basal WC grains was measured at varying temperatures, ranging from 100 to $700{ }^{\circ} \mathrm{C}(\mathrm{A})$. The plastic index of both basal and prismatic grains (the plastic index of both prismatic orientations is comparable at each temperature) was also measured and subsequently compared at high temperatures (B).

The hardness of both prismatic and basal grains was measured at temperatures up to $700{ }^{\circ} \mathrm{C}$, in steps of $100{ }^{\circ} \mathrm{C}(10$ to 30 indents of each orientation) (Fig.4A). The hardness of all WC grains, measured at $100{ }^{\circ} \mathrm{C}$, was found unchanged as compared to room temperature measurements. The hardness of basal grains was measured almost twice that of prismatic grains all over the range of temperatures, in good agreement with previous work [14]. As the temperature increases, from 100 to $400{ }^{\circ} \mathrm{C}$, all WC grains progressively soften regardless of their orientation. At a temperature of about $500-600{ }^{\circ} \mathrm{C}$, a more significant drop in the hardness of all WC grains was observed, followed by further decline up to $700{ }^{\circ} \mathrm{C}$. While the hardness of basal grains seems to follow a roughly linear downtrend over the whole range of temperature, the hardness of prismatic WC grains appears less affected in the temperature 
range of 100 to $400{ }^{\circ} \mathrm{C}$. At temperatures higher than $400{ }^{\circ} \mathrm{C}$, significant softening occurs leading to similar reduction in hardness for both WC orientations, down by about $70-75 \%$ at $700{ }^{\circ} \mathrm{C}$ as compared to hardness measured at room temperature. The linear decrease in hardness with increasing temperature (from 100 to $400{ }^{\circ} \mathrm{C}$ ) observed in basal grains is indicative of a different stress relaxation mechanism as compared to prismatic grains. In order to further investigate any anisotropy in the deformation of WC grains, the plasticity of both prismatic and basal WC crystal orientations was measured and compared over the whole range of temperatures, up to $700{ }^{\circ} \mathrm{C}$ (Fig.4B). For temperatures up to $200{ }^{\circ} \mathrm{C}$, the plastic index of both prismatic and basal grains was found similar. As the temperature increases, the plasticity of prismatic grains becomes gradually more pronounced than that of basal grains, up to $400{ }^{\circ} \mathrm{C}$. At $500{ }^{\circ} \mathrm{C}$, the plasticity of WC grains become drastically more anisotropic, with prismatic grains exhibiting significantly more plastic deformation than basal grains. At temperatures exceeding $500{ }^{\circ} \mathrm{C}$, the trend reversed as basal grains appear to undergo large plastic deformation at these temperatures. Previous work, at larger indentation length scales, also identified a significant drop in the hardness of the overall ultrafine WC-Co material at a temperature of $600{ }^{\circ} \mathrm{C}$, which may have been the result of change in WC grain boundary strength and/or Co phase softening [23]. However, the latter may not apply to WC-Co with larger grains $(>1 \mu \mathrm{m})$. Hence, in order to understand the softening of WC and the anisotropy in plastic flow, both prismatic and basal WC grains were spherically indented at varying temperatures, which coupled with $\mathrm{ECCl}$ allowed to investigate the formation of plastic deformation in individual WC grains under the spherical indenter.

\section{$\mathrm{ECCl}$ observation of deformation}

\section{Room Temperature}

Spherical nanoindentation ( $5 \mu \mathrm{m}$ radius) was performed in the centre of coarse $(>15 \mu \mathrm{m})$ (0001) basal and ( $\overline{1} 2 \overline{1} 0)$ prismatic grains at room temperature (Fig.5). ECCl micrographs were collected before and after indentation to separate pre- from post-nanoindentation damage on the surface of the grains. It is worth noting that due to the nature of the technique, $\mathrm{ECCl}$ allows for defects to be visualised from the surface of the grain down to a depth of few tens of nanometres, as backscattered electrons can channel through the lattice of the crystal. Top view and cross-section ECCI micrographs of indented grains clearly shows evidence of plastic deformation in the vicinity of the indent imprint. The plastic field generated by the spherical indenter was evidenced by local changes in electron channelling contrast in the vicinity of the imprint (local lattice defects causing high intensity pixels) [37], which becomes even clearer when multiple channelling conditions were satisfied and compiled together into movies (Supplementary information). The top-view $\mathrm{ECCl}$ micrograph of the indented prismatic grain (Fig.5B) reveals the presence of parallel slip lines, and which EBSD shows are parallel to plane traces of the (1 $\overline{1} 00)$ and $(01 \overline{1} 0)$ type (Fig.5i), consistent with slip on these two systems as observed in previous work [20]. The plastic field tends to preferentially diffuse outwards, parallel to the slip line direction, accommodating the stresses within "clover-leaf" semi-circular rings (see supplementary information). Less plasticity (as revealed by the local changes in channelling contrast) was observed in the crosssection (Fig.5C) of the indented prismatic grain as compared to observation made in top-view

but it does show intercepting slip lines, consistent with slip on prismatic planes [6, 20]. Slip lines intercepting each other at $60^{\circ}$, consistent with prismatic slip on planes of the type $(1 \overline{1} 00)$, 
$(10 \overline{1} 0)$ and $(01 \overline{1} 0)$, were also clearly observed at the surface of the indented basal grain, accompanied with limited plastic flow across the surface of the basal grain (Fig.5E). However, contrast in the cross-section ECCI micrograph shows plasticity is limited to a region immediately beneath the indent, preferentially diffusing perpendicularly to the surface of the basal grain (along the indent loading direction) (Fig.5F). In agreement with ECCl investigation, whilst the transition from the elastic to plastic regime appears to occur at a similar load for both WC grain orientations, a larger area under the P-h curve of the indented prismatic grain was observed, indicative of more plasticity during spherical indentation loading (Fig.5G-H).
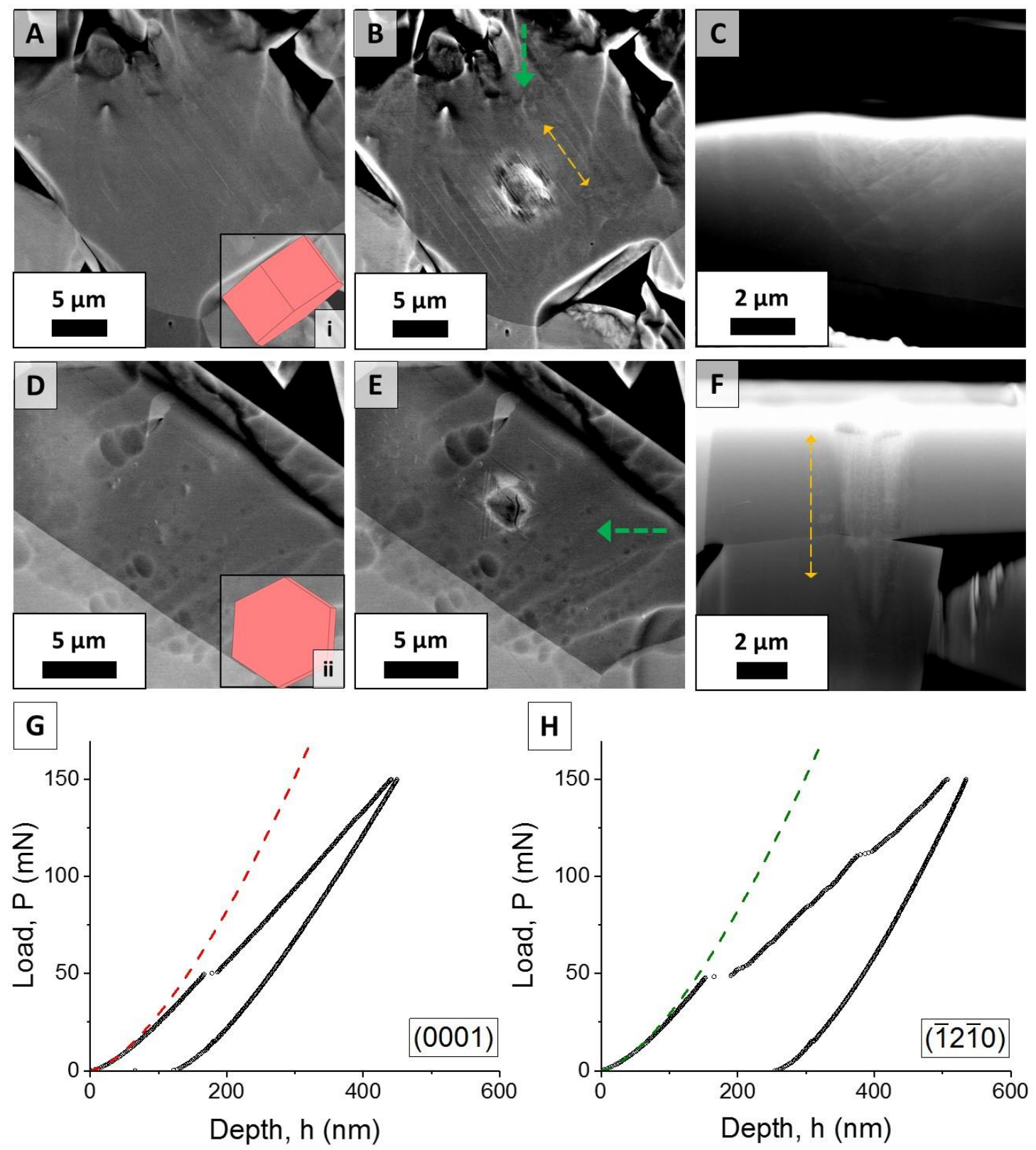

Figure 5. Plastic deformation in WC basal and prismatic grains at room temperature. Top view ECCI micrographs of WC $(\overline{1} 2 \overline{1} 0)$ prismatic and (0001) basal grains before and after spherical indentation ( $5 \mu \mathrm{m}$ radius) at room temperature (A-B and $D-E$, respectively), with their hexagonal unit cell orientation acquired from EBSD ( $i$ and ii, respectively) . Cross-section $\mathrm{ECCl}$ micrographs of WC $(\overline{1} 2 \overline{1} 0)$ prismatic and (0001) basal grains after spherical indentation $(5 \mu \mathrm{m}$ radius) at room temperature ( $C$ and $F$, respectively). The green dashed arrows indicate the milling direction used to acquire the cross-section $\mathrm{ECCl}$ micrographs, while the dashed orange line pinpoints the direction along which plastic deformation generated from the spherical indent preferentially diffuse. Spherical P-h curves (5 $\mu \mathrm{m}$ radius) of the indented (0001) basal and ( $\overline{1} 2 \overline{1} 0)$ prismatic WC grains ( $G$ and $H$, respectively) - a Hertzian solution was fitted on both curves to pinpoint the transition from elastic to plastic deformation during indentation loading (dashed curves). 


\section{High Temperature}

As the temperature increases to 200 and $400{ }^{\circ} \mathrm{C}$, ECCl investigation of the deformation around indents in basal grains revealed similar shape and dimensions to ambient conditions, while the number of intercepting slip lines increases around the indent (Fig.6A-B), creating a sink-in topographical feature as a result of work-hardening $[16,20]$. At temperatures up to $400{ }^{\circ} \mathrm{C}$, cracks were initiated within the indent imprint. At $600{ }^{\circ} \mathrm{C}$, basal grains failed (Fig.6C) by severe cracking. Cracks were also accompanied with an increased number of intercepting slip lines, triggered farther away from the imprint. $\mathrm{ECCl}$ movies clearly revealed the expansion of the plastic field within the basal plane at $600{ }^{\circ} \mathrm{C}$ compared to limited plastic deformation at lower temperatures in this plane (Supplementary information). While plastic deformation was not seen in the top view to significantly diffuse across the basal plane, cross-section ECCI micrographs revealed plasticity preferentially propagating perpendicular to the basal plane (Fig.6D-F), as previously observed for grains indented at room temperature. For temperatures up to $400{ }^{\circ} \mathrm{C}$, cracks that were initiated in the indent imprint did not seem to propagate within the grains. However, at $600{ }^{\circ} \mathrm{C}$, the basal grain exhibited large cracks, propagating downwards in a dramatic manner, parallel to the trace a prismatic grain would make with the surface, with plasticity seen across the entire cross-section of the grain (Fig.6F).
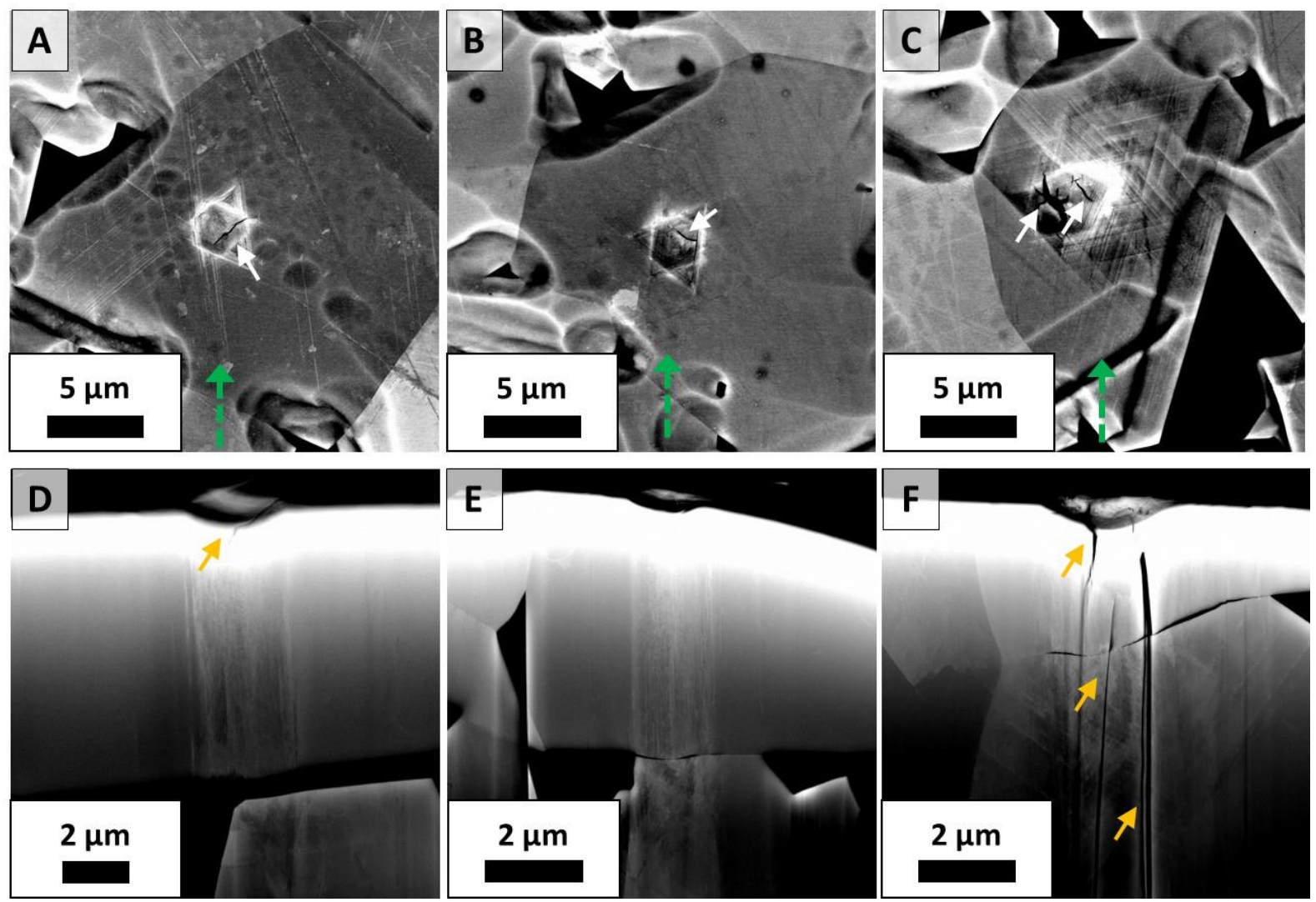

Figure 6. Plastic deformation in WC basal grains at varying temperatures. Top-view and cross-section ECCI micrographs of indented WC (0001) basal grains with a spherical indenter $\left(5 \mu \mathrm{m}\right.$ radius) at $200{ }^{\circ} \mathrm{C}$ temperature ( $\mathrm{A}$ and $\mathrm{D}$ respectively), $400{ }^{\circ} \mathrm{C}$ ( $\mathrm{B}$ and $\mathrm{E}$, respectively) and $600^{\circ} \mathrm{C}(\mathrm{C}$ and $\mathrm{F}$, respectively). The white and orange arrows pinpoint the location of cracks in the imprint and in the cross-section of the grains, respectively. The green dashed arrows indicate the milling direction used to acquire the cross-section ECCI micrographs. 
When indenting prismatic grains (Fig.7), up to $400{ }^{\circ} \mathrm{C}$, the plastic field tends to preferentially diffuse parallel and between the slip lines produced on the surface of the grains, with growing dimensions as the temperature increases (Fig.7A-B). At $600{ }^{\circ} \mathrm{C}$, in a manner similar to the basal grains, prismatic grains failed, triggering large cracks and a plastic field propagating across the full grain surface (Fig.7C). In agreement with the previous basal grain observations a number of the cracks were observed to lie parallel with the slip lines and thus probably on the prismatic plane. At $400{ }^{\circ} \mathrm{C}$ (Fig.7E), some slip can be seen nearly perpendicular to the surface in addition to the prismatic slip, but at $600{ }^{\circ} \mathrm{C}$ multiple cracks were triggered, forming obvious steps in the cross-section (Fig.7F). In addition to the cracks, plastic deformation was observed within the entire cross-section of the grain at $600{ }^{\circ} \mathrm{C}$.
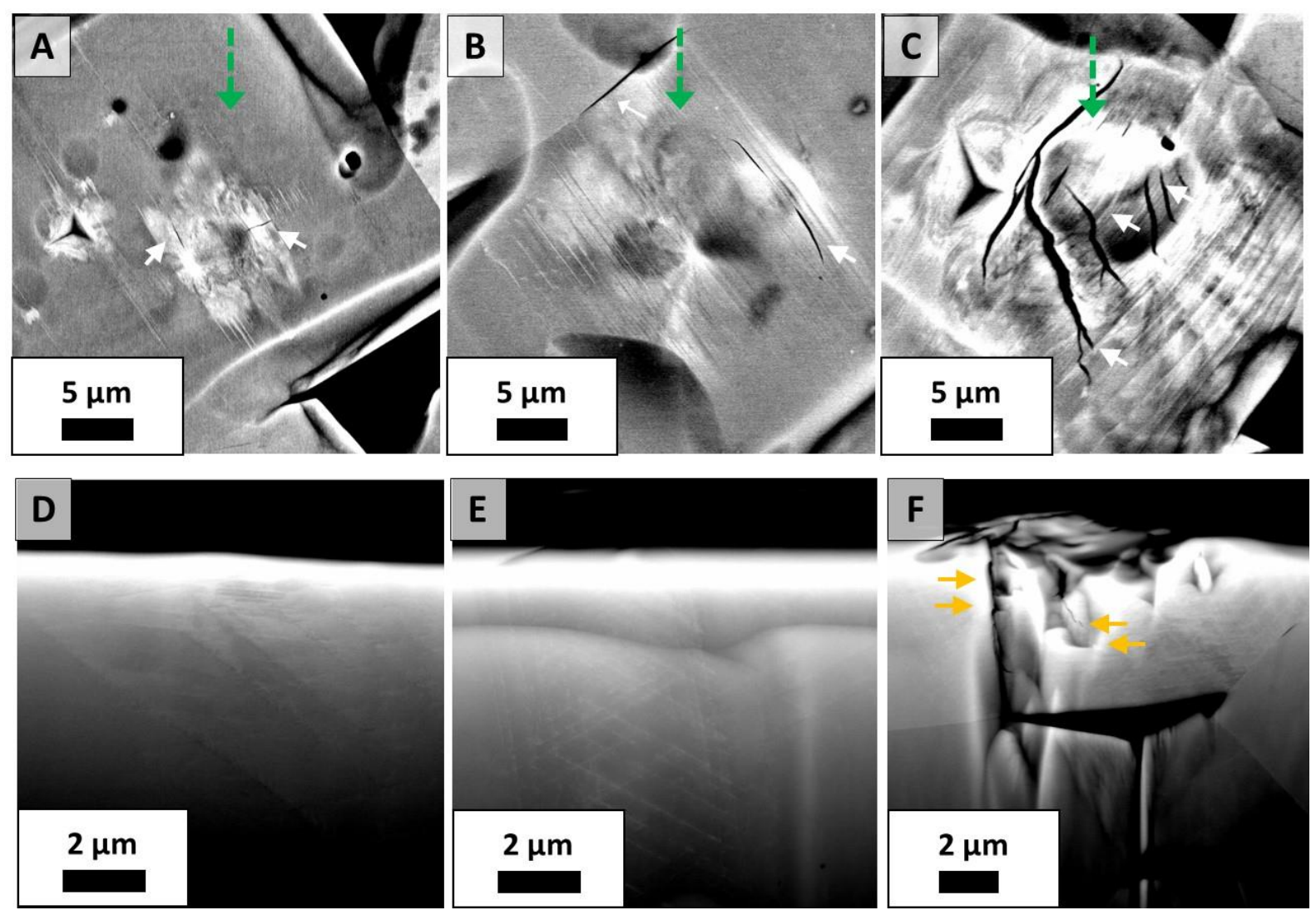

Figure 7. Plastic deformation in WC prismatic grains at varying temperatures. Top-view and cross-section ECCI micrographs of indented WC prismatic grains with a spherical indenter $\left(5 \mu \mathrm{m}\right.$ radius) at $200{ }^{\circ} \mathrm{C}$ ( $\mathrm{A}$ and $\mathrm{D}$, respectively - $(01 \overline{1} 0)$ plane), $400{ }^{\circ} \mathrm{C}$ ( $\mathrm{B}$ and $\mathrm{E}$, respectively - $(\overline{1} 2 \overline{1} 0)$ plane) and $600{ }^{\circ} \mathrm{C}(\mathrm{C}$ and $\mathrm{F}$, respectively - $(01 \overline{1} 0)$ plane). The white arrows pinpoint the location of cracks in the imprint while the green dashed arrows indicate the milling direction used to acquire the crosssection ECCI micrographs. The orange arrows highlight failure of the prismatic grains, along the indent cross-section, forming steps indicative of cracks within the prismatic plane.

Whilst plastic deformation intensifies in both WC grains with temperature, leading to higher densities of slip bands as observed in previous work [22], the anisotropic plastic flow in WC crystals, and more especially, the difference in the plastic index measured for basal and prismatic grains, can therefore be explained by the preferential accommodation of stress via the initiation of different slip system and cracking. Stresses were found to be released through 
cracking, probably on the prismatic plane, when indenting the basal plane of WC. Anisotropy in plastic flow between crystallographic orientation were found to significantly influence the deformation of $\mathrm{WC}$ at temperatures up to $500{ }^{\circ} \mathrm{C}$. At temperature exceeding $500{ }^{\circ} \mathrm{C}$, an increase in the plasticity in both basal and prismatic grains can be attributed in the failure of the grains, associated with severe cracking within the prismatic plane and large plasticity in multiple directions.

\section{Conclusions}

Individual phases and grain orientations in WC-Co cemented carbide were investigated by means of high temperature nanoindentation and electron microscopy using a limited number of indents while directly targeting grains with varying dimensions. While basal grains were about twice harder than prismatic grains, an investigation of WC grain size effect revealed that a boundary strengthening effect occurs in grains with restricted dimensions (from about 0.5 to $2 \mu \mathrm{m}$ - plastic deformation dominated by dislocation activity). High temperature nanoindentation of individual WC grains, with prismatic and basal orientation, allowed for the study of hardness and plastic deformation anisotropy at temperatures up to $700{ }^{\circ} \mathrm{C}$. While all grains orientations were found to soften with increasing temperature, a significant drop in hardness was measured at temperature exceeding $500{ }^{\circ} \mathrm{C}$ with hardness reduction up to 70 $75 \%$ at $700{ }^{\circ} \mathrm{C}$. The deformation behaviour of WC grains was investigated by means of $\mathrm{ECCl}$, suggesting slip on prismatic planes. Failure of all WC grains by cracking was observed at temperature starting from $500{ }^{\circ} \mathrm{C}$, triggering thermally activated deformation mechanisms in both prismatic and basal planes. The collected mechanical information from the different orientations of WC grains at high temperature represent useful data to understand the performance of WC-Co in service conditions but also valuable properties in order to improve performance and lifetime through microstructure design of the materials.

\section{Acknowledgements}

This work has been supported by the EMPIR 14IND03 Strength-ABLE Grant and the National Measurement System Programme of the UK government's Department for Business, Energy \& Industrial Strategy (BEIS). Members of the Research Group of the British Hardmetals Association are thanked for their comments.

\section{Additional information}

The authors declare no competing interests

\section{References}

1. Exner, H., Physical and chemical nature of cemented carbides. International metals reviews, 1979. 24(1): p. 149-173.

2. Roebuck, B. and E. Almond, Deformation and fracture processes and the physical metallurgy of WC-Co hardmetals. International Materials Reviews, 1988. 33(1): p. 90-112.

3. Upadhyaya, G.S., Cemented tungsten carbides: production, properties and testing. 1998: William Andrew. 
4. Schwarzkopf, P. and R. Kieffer, Refractory hard metals: borides, carbides, nitrides, and silicides; the basic constituents of cemented hard metals and their use as high-temperature materials. 1953: Macmillan.

5. Gee, M., et al., Constituent phase nanoindentation of WC/Co and Ti $(C, N)$ hard metals. Materials Science and Engineering: A, 1996. 209(1-2): p. 128-136.

6. Rowcliffe, D.J., et al., Compressive deformation and fracture in WC materials. Materials Science and Engineering: A, 1988. 105: p. 299-303.

7. Roa, J.J., et al., Hall-Petch strengthening of the constrained metallic binder in WC-Co cemented carbides: Experimental assessment by means of massive nanoindentation and statistical analysis. Materials Science and Engineering: A, 2016. 676: p. 487-491.

8. Roa, J.J., et al., Intrinsic hardness of constitutive phases in WC-Co composites: Nanoindentation testing, statistical analysis, WC crystal orientation effects and flow stress for the constrained metallic binder. Journal of the European Ceramic Society, 2015. 35(13): p. 3419-3425.

9. Duszová, A., et al., Nanoindentation of WC-Co hardmetals. Journal of the European Ceramic Society, 2013. 33(12): p. 2227-2232.

10. Bonache, V., et al., Nanoindentation study of WC-12Co hardmetals obtained from nanocrystalline powders: Evaluation of hardness and modulus on individual phases. Materials Science and Engineering: A, 2010. 527(12): p. 2935-2941.

11. Roa, J.J., et al., Mapping of mechanical properties at microstructural length scale in WC-Co cemented carbides: Assessment of hardness and elastic modulus by means of high speed massive nanoindentation and statistical analysis. International Journal of Refractory Metals and Hard Materials, 2018. 75: p. 211-217.

12. Cuadrado, N., et al., Effect of Crystal Anisotropy on the Mechanical Properties of WC Embedded in WC-Co Cemented Carbides. PM-Hard Mater, 2011. 1.

13. Roebuck, B., P. Klose, and K.P. Mingard, Hardness of hexagonal tungsten carbide crystals as a function of orientation. Acta Materialia, 2012. 60(17): p. 6131-6143.

14. Lee, M., High temperature hardness of tungsten carbide. Metallurgical Transactions A, 1983. 14(8): p. 1625-1629.

15. Bl'anda, M., et al., Indentation fatigue of WC grains in WC-Co composite. Journal of the European Ceramic Society, 2014. 34(14): p. 3407-3412.

16. Csanádi, T., et al., Orientation-dependent hardness and nanoindentation-induced deformation mechanisms of WC crystals. Acta Materialia, 2015. 83: p. 397-407.

17. French, D.N. and D.A. Thomas, Hardness anisotropy and slip in WC crystals. Trans. Met. Soc. AIME, 1965. 233.

18. Pons, L., Plastic properties in tungsten monocarbide, Anisotropy in single-crystal refractory compounds, Vahldiek. 1968, Fred W., Mersol, Stanley A, New York.

19. Takahashi, T. and E. Freise, Determination of the slip systems in single crystals of tungsten monocarbide. Philosophical Magazine, 1965. 12(115): p. 1-8.

20. Luyckx, S., et al., The anisotropic work-hardening of WC crystals. Acta metallurgica et materialia, 1992. 40(7): p. 1623-1627.

21. D. J., R., Compressive Deformation and Fracture in WC Materials. materials Science and Engineering: A, 1988. 105/106: p. 299-303.

22. $\mathrm{Hu}, \mathrm{H}$., et al., How hard metal becomes soft: crystallographic analysis on the mechanical behavior of ultra-coarse cemented carbide. Acta Crystallographica Section B: Structural Science, Crystal Engineering and Materials, 2019. 75(6).

23. Vornberger, A., et al., Influence of microstructure on hardness and thermal conductivity of hardmetals. International Journal of Refractory Metals and Hard Materials, 2020. 88.

24. Beake, B.D. and J.F. Smith, High-temperature nanoindentation testing of fused silica and other materials. Philosophical Magazine A, 2002. 82(10): p. 2179-2186. 
25. Conte, M., et al., Novel high temperature vacuum nanoindentation system with active surface referencing and non-contact heating for measurements up to 800 degrees $C$. Rev Sci Instrum, 2019. 90(4): p. 045105.

26. Harris, A.J., et al., Development of high temperature nanoindentation methodology and its application in the nanoindentation of polycrystalline tungsten in vacuum to $950 \mathrm{C}$. Experimental Mechanics, 2017. 57(7): p. 1115-1126.

27. Wheeler, J., et al., High temperature nanoindentation: The state of the art and future challenges. Current Opinion in Solid State and Materials Science, 2015. 19(6): p. 354-366.

28. Wheeler, J.M. and J. Michler, Invited Article: Indenter materials for high temperature nanoindentation. Rev Sci Instrum, 2013. 84(10): p. 101301.

29. Gibson, J.S.-L., et al., On extracting mechanical properties from nanoindentation at temperatures up to 1000 C. Extreme Mechanics Letters, 2017. 17: p. 43-49.

30. Sudharshan Phani, P. and W.C. Oliver, A critical assessment of the effect of indentation spacing on the measurement of hardness and modulus using instrumented indentation testing. Materials \& Design, 2019. 164.

31. Hou, X.D., C.L.M. Alvarez, and N.M. Jennett, Establishing isothermal contact at a known temperature under thermal equilibrium in elevated temperature instrumented indentation testing. Measurement Science and Technology, 2017. 28(2).

32. Everitt, N.M., M.I. Davies, and J.F. Smith, High temperature nanoindentation - the importance of isothermal contact. Philosophical Magazine, 2011. 91(7-9): p. 1221-1244.

33. Schuh, C.A., C.E. Packard, and A.C. Lund, Nanoindentation and contact-mode imaging at high temperatures. Journal of materials research, 2006. 21(3): p. 725-736.

34. Oliver, W.C. and G.M. Pharr, An improved technique for determining hardness and elastic modulus using load and displacement sensing indentation experiments. Journal of materials research, 1992. 7(6): p. 1564-1583.

35. Oliver, W.C. and G.M. Pharr, Measurement of hardness and elastic modulus by instrumented indentation: Advances in understanding and refinements to methodology. Journal of materials research, 2004. 19(1): p. 3-20.

36. Renger, A., Johnson, KL, Contact Mechanics. Cambridge etc., Cambridge University Press 1985. XII, 452 pp., 1 17.50 P/B. ISBN 0521347963. ZAMM-Journal of Applied Mathematics and Mechanics/Zeitschrift für Angewandte Mathematik und Mechanik, 1989. 69(7): p. 214214.

37. Zaefferer, S. and N.-N. Elhami, Theory and application of electron channelling contrast imaging under controlled diffraction conditions. Acta Materialia, 2014. 75: p. 20-50.

38. Joy, D.C., D.E. Newbury, and D.L. Davidson, Electron channeling patterns in the scanning electron microscope. Journal of Applied Physics, 1982. 53(8): p. R81-R122.

39. Lafond, C., et al., Electron CHanneling ORientation Determination (eCHORD): An original approach to crystalline orientation mapping. Ultramicroscopy, 2018. 186: p. 146-149.

40. L'hôte, G., et al., Rotational-Electron Channeling Contrast Imaging analysis of dislocation structure in fatigued copper single crystal. Scripta Materialia, 2019. 162: p. 103-107.

41. Jablon, B.M., et al., Subgrain structure and dislocations in WC-Co hard metals revealed by electron channelling contrast imaging. International Journal of Refractory Metals and Hard Materials, 2020. 87.

42. Schindelin, J., et al., Fiji: an open-source platform for biological-image analysis. Nature Methods, 2012. 9(7): p. 676-682.

43. Hansen, N., Hall-Petch relation and boundary strengthening. Scripta Materialia, 2004. 51(8): p. 801-806.

44. Chang, S.-Y. and T.-K. Chang, Grain size effect on nanomechanical properties and deformation behavior of copper under nanoindentation test. Journal of Applied Physics, 2007. 101(3). 